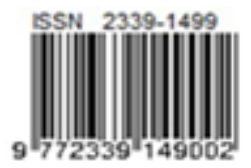

\title{
Analisis Strategi Pemasaran Mengunakan Metode Quantitative Strategic Planning Matrik (QSPM) Studi Kasus : Borneo Project
}

\author{
Anas Mujahid', Murianai Emelda Isharyani ${ }^{2}$, Dharma Widada ${ }^{3}$ \\ 1,2,3) Fakultas Teknik, Jurusan Teknik Industri, Universitas Mulawarman \\ Kampus Gn Kelua, Jl. Sambaliung No. 9 Samarinda 75119 \\ Email: anasmujahid2@gmail.com, dekan@ftunmul.ac.id
}

\begin{abstract}
Borneo Project is a new business in the field of ordering services of various types of clothing. In doing its marketing strategy Borneo Project relies on marketing through friendship, word of mouth from one to another one and using social media as a marketing tool. This has not had a much positive effect on sales in Borneo Project. Therefore it is necessary to analyze the marketing strategy that can be applied in Borneo Project.

Determining the strategy carried out in three stages: an input stage, matching stage, and the stage of the decision. The input stage is done by using Internal Factor Evaluation Matrix (IFE) and External Factor Evaluation Matrix (EFE). In the IFE matrix, obtained a total score of 2.407, while the EFE Matrix obtained score of 2.831. Based on internal and external factor analysis then matching phase with IE Matrix method and SWOT Matrix. The final stage was the decision stage used QSPM method. QSPM is used to evaluate alternative strategies obtained in the SWOT Matrix, then rank them. The first rank is the strategy of applying for credit funds, seeking investors or business joint venture partners and seeking financial assistance from corporate CSR with the acquisition of power score Pull of 5,824. Alternative strategies are prioritized to be applied is to ask a credit fund, seek a joint venture partner and investor or business and are looking for financial aid CSR.
\end{abstract}

Keywords: Marketing Strategy, Borneo Project, QSPM

\section{Abstrak}

Borneo Project adalah sebuah usaha baru di bidang jasa pemesanan berbagai macam jenis pakaian. Dalam melakukan strategi pemasarannya Borneo Project mengandalkan pemasaran melalui pertemanan, dari mulut ke mulut dan mengunakan media sosial sebagai sarana pemasran. Hal ini belum banyak perpengaruh positif terhadap penjulan di Borneo Project. Untuk itu diperlukan Analisis strategi pemasran yang dapat diterapkan di Borneo Project.

Penentuan strategi diterapkan melalui tiga langkah, yaitu tahap input, tahap pencocokan, dan tahap keputusan. Tahap input dilakukan dengan menggunakan metode Matriks Evaluasi Faktor Internal (IFE) dan Matriks Evaluasi Faktor Eksternal (EFE). Pada matriks IFE, didapatkan total skor sebesar 2,417, sedangkan pada Matriks EFE didapatkan skor sebesar 2,831. Berdasarkan analisis faktor internal dan eksternal selanjutnya dilakukan tahap pencocokan dengan metode Matriks IE dan Matriks SWOT. Matriks IE menggunakan skor yang didapatkan pada matriks IFE dan Matriks EFE menunjukkan bahwa Borneo Project berada di sel V, dengan strategi yang dapat digunakan yaitu menjaga dan mempertahankan. Berdasarkan strategi tersebut serta faktor internal dan faktor eksternal, maka dirumuskan strategi dengan menggunakan Matriks SWOT. Delapan alternatif strategi didapatkan dengan menggunakan Matriks SWOT. Tahap terakhir adalah tahap keputusan dengan menggunakan metode QSPM. QSPM digunakan untuk mengevaluasi alternatif strategi yang didapatkan pada Matriks SWOT, kemudian memberi peringkat pada strategi-strategi tersebut. Peringkat pertama, yaitu strategi Mengajukan dana kredit, mencari investor atau partner patungan bisnis dan mencari bantuan dana dari csr perusahaan dengan perolehan skor daya tarik sebesar 5,824 . Alternatif strategi yang diprioritaskan untuk diterapkan adalah Mengajukan dana kredit, mencari investor atau partner patungan bisnis dan mencari bantuan dana dari CSR perusahaan.

Kata Kunci: Strategi Pemasaran, Borneo Project, QSPM. 


\section{Pendahuluan}

Indonesia merupakan negara dengan jumlah peduduk terbesar ke 4 di dunia. Badan Pusat Statistik Nasional memberikan keterangan dan data resmi mengenai jumlah penduduk Indonesia pada sensus penduduk tahun 2010 berjumlah 237,6 juta jiwa. Menurut badan pusat stastistik pertumbuhan penduduk Indonesia rata-rata 1.49\% per tahun (Biro Pusat Statistik, 2018).

Gaya berpakaian di era modernisasi saat ini ada banyak pakaian yang harus dimiliki oleh setiap individu. Hal ini dimaksudkan sebagai penunjang penampilan dan aktivitas yang disesuaikan dengan keadaaan pada suatu tempat. Diantara pakain tersebut adalah pakaian sehari hari, pakaian kerja atau organisasi, pakaian untuk beribadah, seragam olahraga dan lain sebagainya yang digunakan untuk menyesuaikan penampilan. Untuk itu usaha dibidang pembuatan pakaian atau konfeksi masih terus bisa berkembang.

Borneo Project adalah sebuah usaha di bidang pemesanan berbagai macam jenis pakaian. Usaha ini didirikan pada tanggal 10 Agustus 2016, dalam melaksanakan kegiatan usahanya Borneo Project menerima pemesanan berbagai macam kebutuhan pakaian diantaranya adalah kaos, pakaian dinas harian, jaket, Almamater, Jas lab, topi dan berbagai macam kebutuhan pakain untuk organisasi, perkantoran, pendidikan dan berbagai macam bidang usaha.

Persoalan yang menjadi masalah bagi pemasaran produk pakaian ini adalah belum banyak upaya dari Borneo Project untuk mengembangkan usahanya sehingga setiap bulannya belum banyak peningkatan dalam penjualan. Untuk itu Borneo Project dirasa perlu merumuskan strategi pemasaran agar dapat berkembang dalam memasarkan produknya dan dapat bersaing dengan usaha serupa yang telah ada.

Analisis starategi yang dilakukan adalah menggunakan metode Quantitative Strategic Planning Matrix (QSPM). Quantitative Strategic Planning Matrix (QSPM) secara objektif mampu menunjukkan strategi mana yang terbaik dari berbagai alternative (Mahfud, T. 2017) (Mas'ud E dan Imam S.2016) (Puspitasari N,. B., Rumita., Rani, Pratama G. Y., 2013) (Purwandari, S., 2015). Identifikasi dari faktor internal dan external yang telah dirumuskan menghasilkan matrik IE yang dapat diperiksa secara berurutan dan bersamaan dengan Analisis SWOT, serta tidak ada batas untuk jumlah strategi untuk dapat dievaluasi secara bersamaan. Hal ini dilakukan guna menetapkan strategi terbaik diantara strategi-strategi yang telah dirumuskan sebelumnya.

Hasil analisis ini diharapkan dapat membantu Borneo Project dalam melakukan pengembangan dan dapat bersaing dalam memasarkan produk Konfeksinya.

\section{Metodologi Penelitian}

Usaha konfeksi dapat didefinisikan sebagai pakaian dan sebagainya yang dibuat secara massal yang dijual dalam keadaan jadi, tidak diukur menurut pesanan, tetapi menurut ukuran yang sudah ditentukan perusahaan (Kamus Besar Bahasa Indonesia, 2017).

Pemasaran merupakan proses aktivitas terjadi karena pengaruh bermacam faktor sosial, budaya, politik, ekonomi, dan manajerial. Berbagai faktor tersebut berpengaruh terhadap masing-masing individu maupun kelompok mendapatkan kebutuhan dan keinginan dengan menciptakan, menawarkan, menukarkan produk yang memiliki nilai komoditas (Rangkuti, 2006).

Manajemen pemasaran (marketing management) sebagai seni dan ilmu memilih pasar sasaran dan memilih, mempertahankan, serta menumbuhkan pelanggan dengan menciptakan, menghantarkan, dan mengkomunikasikan nilai pelanggan yang unggul (Kolter, P., Keller, K.L., 2009).

Menurut David (2009) faktor-faktor strategis internal yang dapat dianalisis serta dapat mempengaruhi kekuatan dan kelemahan internal antara lain meliputi faktor manajemen yang meliputi aktivitas perencanaan, aktivitas pengorganisasian, aktivitas pemotivasian, aktivitas penempatan staf, serta aktivitas pengontrolan. Faktor kedua adalah pemasaran yang meliputi penjualan produk/jasa, perencanaan produk/jasa, penetapan harga, distribusi, riset pemasaran, dan menganalisis peluang. Faktor keuangan merupakan faktor ketiga yang perlu dianalisis meliputi keputusan investasi, dividen, serta pembiayaan. Faktor ke empat adalah produksi yang meliputi semua aktivitas yang mengubah input menjadi barang atau jasa. Faktor ke lima adalah penelitian dan pengembangan. Sedangkan faktor yang ke enam adalah sistem informasi manajemen untuk mempercepat dan meningkatkan kinerja 
pengambilan keputusan manajerial pada sebuah bisnis.

Analisis lingkungan eksternal bertujuan untuk membangun daftar terbatas dari peluang yang lebih menguntungkan pada sebuah perusahaan dan termasuk ancaman yang harus dihindarinya (Suharno dan Sutarso, 2010). . Menurut Suharno dan Sutarso (2010) analisis lingkungan eksternal perusahaan terdiri dari dua komponen pokok yaitu lingkungan mikro dan lingkungan makro.

Menurut David (2009), Matriks Evaluasi Faktor Eksternal bertujuan untuk meringkas dan mengevaluasi informasi sosial budaya, ekonomi, lingkungan, demografi, politik, pemerintah, hukum, teknologi, bahkan persaingan.

Menurut David (2009), matriks IFE digunakan untuk meringkas serta untuk mengevaluasi internal terhadap kekuatan maupun kelemahan utama dalam area-area fungsional bisnis, serta menjadi landasan untuk mengidentifikasi serta mengevaluasi hubungan di antara area fungsional bisnis tersebut. Proses penilaian intuitif juga digunakan dalam mengembangkan matriks evaluasi faktor internal.

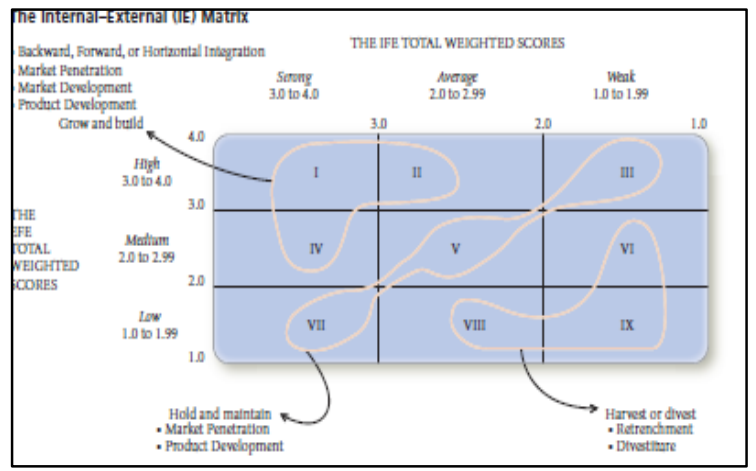

Gambar 1. The Internal - External Matrix

Menurut David (2009), matriks internal ekstrenal (IE) adalah salah satu alat analisis yang menggabungkan tehnik analisis EFE matriks dan IFE matriks. Matriks internalekstrenal (IE) dapat dilihat pada gambar 1.

Tiga implikasi dalam intenal-eksternal (IE) matriks dapat dilihat sebagai berikut David (2009):

\section{Sel I, II, IV}

Dapat digambarkan bahwa perusahaan dalam area "growth and build". Strategi yang dapat diterapkan adalah dengan menerapkan strategi intensif atau strategi integratif.

2. Sel III, V, VII

Dapat digambarkan bahwa perusahaan dalam area "hold and maintain". Strategi yang dapat dilakukan adalah dengan menerapkan penetrasi pasar dan pengembangan produk.

3. Sel VI, VIII, IX

Dapat digambarkan bahwa perusahaan dalam area "harvest atau divest". Perusahaan dapat melakukan strategi likuidasi, divestasi, dan pengurangan usaha.

Matriks SWOT adalah alat yang dapat dipakai untuk menganalisis faktor-faktor strategis dari organisasi. Matriks ini mampu menganalisis secara gamblang mengenai peluang serta ancaman internal serta eksternal yang dihadapi perusahaan juga dapat untuk mengevaluasi kekuatan dan kelemahan yang dimilikinya (Rangkuti, 2006).

\begin{tabular}{|c|c|c|}
\hline EFE & $\begin{array}{l}\text { STRENGHTS (S) } \\
\text { Tentukan 5-10 faktor } \\
\text { kekuatan internal }\end{array}$ & $\begin{array}{l}\text { WEAKNESSES (W) } \\
\text { Tentukan 5-10 faktor } \\
\text { kelemahan internal }\end{array}$ \\
\hline $\begin{array}{l}\text { OPPORTUNIT } \\
\text { IES (O) } \\
\text { Tentukan 5-10 } \\
\text { faktor peluang } \\
\text { eksternal }\end{array}$ & $\begin{array}{l}\text { STRATEGI SO } \\
\text { Ciptakan strategi } \\
\text { yang menggunakan } \\
\text { kekuatan untuk } \\
\text { memanfaatkan } \\
\text { peluang }\end{array}$ & $\begin{array}{l}\text { STRATEGI WO } \\
\text { Ciptakan strategi } \\
\text { yang meminimalkan } \\
\text { kelemahan untuk } \\
\text { memanfaatkan } \\
\text { peluang }\end{array}$ \\
\hline $\begin{array}{l}\text { TREATHTS } \\
\text { (T) } \\
\text { Tentukan 5-10 } \\
\text { faktor ancaman } \\
\text { eksternal }\end{array}$ & $\begin{array}{l}\text { STRATEGI ST } \\
\text { Ciptakan strategi } \\
\text { yang menggunakan } \\
\text { kekuatan untuk } \\
\text { mangatasi ancaman }\end{array}$ & $\begin{array}{l}\text { STRATEGI WT } \\
\text { Ciptakan strategi } \\
\text { yang meminimalkan } \\
\text { kelemahan dan } \\
\text { menghindari } \\
\text { ancaman }\end{array}$ \\
\hline
\end{tabular}

Gambar 2. Matrix SWOT (David, 2009)

Menurut David (2009), teknik Matriks Perencanaan Strategi Kuntitatif (Quantitative Strategic Planing Matriks - QSPM) merupakan salah satu metode analisis dalam literature yang dirancang dalam penentuan daya tarik secara relatif dari berbagai alternative tindakan. Teknik ini secara objektif menunjukkan strategi mana yang terbaik. QSPM menggunakan analisis input dari Tahap 1 dan hasil pencocokan dari analisis Tahap 2 untuk secara objektif menentukkan strategi yang hendak dijalankan diantara strategi-strategi alternatif.

Penelitian ini dilaksanakan di Borneo Project yang merupakan tempat jasa pemesanan segala jenis pakaian yang diperuntukan untuk komunitas, organisasi, Mahasiswa dan pelajar. Borneo Project berlokasi di Jalan Ramania dalam RT 48 No.72 (Gang Rt 48) Kelurahan Sidodadi, Kecamatan Samarinda Ulu, Kota Samarinda.

Data hasil wawancara berupa faktor internal dan eksternal berkaitan dengan pemasaran Borneo Project yang didapatkan dari wawancara oleh 3 narasumber, danData hasil kuisioner berupa pembobotan dan rating untuk 
masing-masing faktor yang mempengaruhi pemasaran Konfeksi. Data penjualan Borneo Project 1 tahun terahir.

Tabel 1. Faktor Evaluasi Internal

\begin{tabular}{|c|c|c|}
\hline Faktor Internal & Kekuatan & Kelemahan \\
\hline Manajemen & 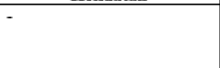 & $\begin{array}{l}\text { Manajemen internal yang } \\
\text { masih harus banyak } \\
\text { ditingkatkan. }\end{array}$ \\
\hline \multirow{5}{*}{ Pemasaran } & $\begin{array}{l}\text { lebih murah dan kuliatas } \\
\text { yang sama dengan produk } \\
\text { dari konfeksi pada } \\
\text { umumnya. }\end{array}$ & $\begin{array}{l}\text { Belum semua sosial media } \\
\text { di gunakan untuk kegiatan } \\
\text { promosi. }\end{array}$ \\
\hline & $\begin{array}{l}\text { memillki banyak jenis } \\
\text { kain yang menyesuaikan } \\
\text { dengan keuangan yang } \\
\text { dimiliki pelanggan. }\end{array}$ & $\begin{array}{l}\text { Borneo Project belum } \\
\text { memiliki tempat dan } \\
\text { galerry yang menetap. }\end{array}$ \\
\hline & $\begin{array}{l}\text { memiliki ratusan warna } \\
\text { baju dari berbagai macam } \\
\text { pabrik dan distributor } \\
\text { kain. }\end{array}$ & - \\
\hline & $\begin{array}{l}\text { memberikan pelayanan } \\
\text { kepada konsumen yaitu } \\
\text { gratis konsultasi, gratis } \\
\text { desain dan gratis ongkir. }\end{array}$ & - \\
\hline & $\begin{array}{l}\text { Memberikan kartu } \\
\text { berlanganan }\end{array}$ & \\
\hline \multirow[t]{2}{*}{ Keuangan } & - & $\begin{array}{l}\text { Mengunakan modal dari } \\
\text { dana pribadi. }\end{array}$ \\
\hline & & $\begin{array}{l}\text { Keuangan yang masih } \\
\text { minim. }\end{array}$ \\
\hline \multirow[b]{2}{*}{ Produksi } & - & $\begin{array}{l}\text { Belum memiliki team } \\
\text { produksi sendiri. }\end{array}$ \\
\hline & & $\begin{array}{l}\text { Belum bisa memproduksi } \\
\text { baju dibawah } 1 \text { lusin. }\end{array}$ \\
\hline Penelitian dan Pengembangan & - & $\begin{array}{l}\text { Tidak ada risert, standar } \\
\text { dan pengembangan } \\
\text { produk. }\end{array}$ \\
\hline
\end{tabular}

\section{Analisi dan Pembahasan}

\subsection{Data Faktor Internal}

Dapat dilihat bahwa hasil perhitungan total skor pada matriks IFE adalah sebesar 2,417. Total skor yang diperoleh kurang dari 2,5, hal ini menunjukkan bahwa lemahnya posisi internal perusahaan dalam menangani kelemahan yang ada dengan kekuatan yang dimiliki.

\subsection{Matrik Evaluasi Faktor Ekternal}

Tabel 2. Matrik Evaluasi Faktor Eksternal

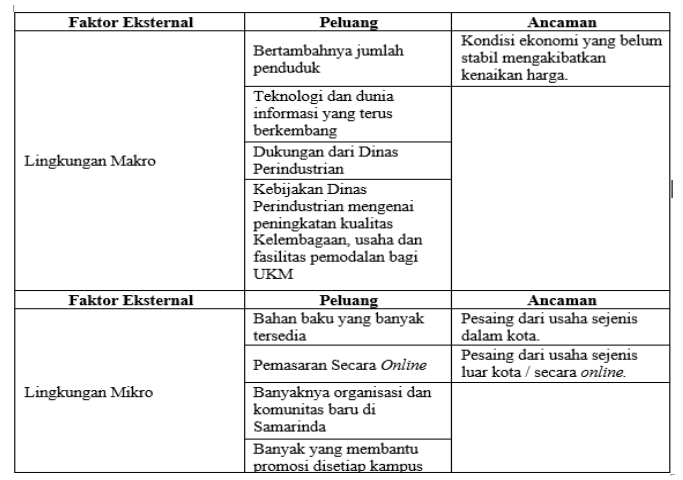

\subsection{Matrik IFE}

Kekuatan utama yang dimiliki oleh Borneo Project adalah lebih murah dan kuliatas yang sama dengan produk dari konveksi pada umumnya dengan total skor sebesar 0,348. Sedangkan kelemahan utama yang dimiliki oleh Borneo Project adalah belum memiliki team produksi sendiri dengan total skor sebesar 0,072 hal ini berpengaruh terhadap kecepatan memproduksi pesanan.
Tabel 3. Matrik Kekuatan Faktor Internal

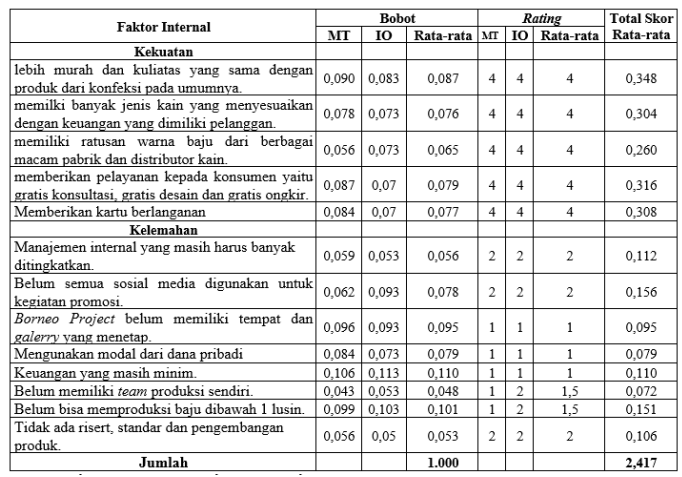

\subsection{Matrik EFE}

Tabel 4. Matrik Evaluasi Faktor Eksternal

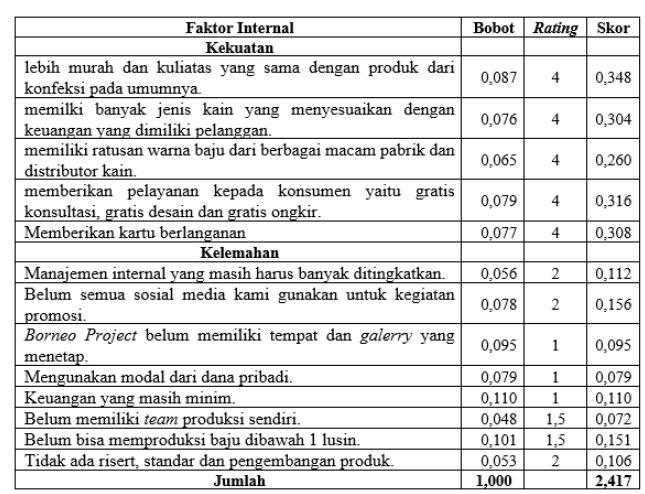

\subsection{Matrik IE (Internal-Eksternal)}

Dapat dilihat bahwa hasil perhitungan total skor pada matriks EFE adalah sebesar 2,831. Total skor yang diperoleh lebih dari 2,5, hal ini menunjukkan bahwa perusahaan mampu merespon dengan baik faktor eksternal dengan memanfaatkan peluang yang ada untuk mengatasi ancaman.

Peluang utama yang dimiliki oleh Borneo Project dengan total skor sebesar 0,360 adalah Pemasaran Secara Online. Sedangkan ancaman utama Borneo Project dengan skor sebesar 0,159 adalah Pesaing dari usaha sejenis dalam kota.

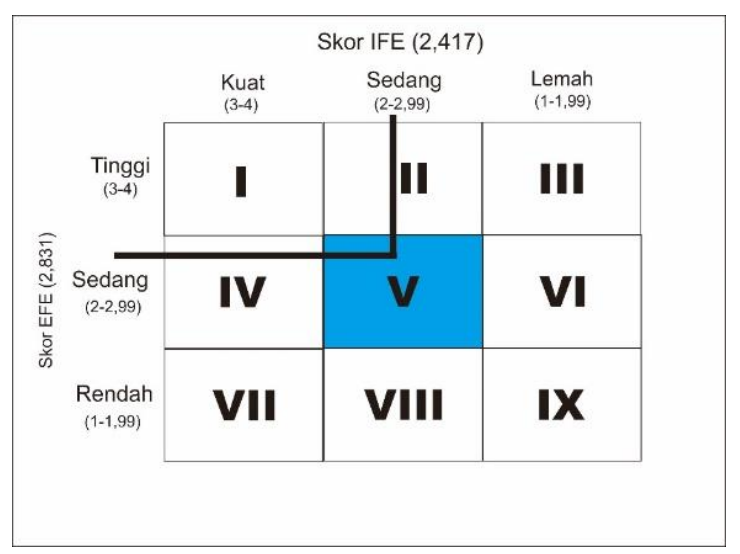

Gambar 2. The Internal - External Matrix Borneo Project 
Skor yang didapatkan pada matriks IFE adalah 2,417, dan skor yang didapatkan pada matriks EFE adalah 2,831, sehingga dapat dilihat pada matriks IE yang tersaji pada Gambar 4.1 diatas menunjukkan bahwa posisi Borneo Project berada pada sel V. Hal ini menunjukkan bahwa Borneo Project berada pada posisi menjaga dan mempertahankan (hold and maintain). Strategi yang dapat digunakan pada posisi hold and maintain ini adalah strategi penetrasi pasar, pengembangan pasar, dan pengembangan produk.

\subsection{Matrik SWOT}

Strategi pemasaran dari usaha konfeksi yang dirumuskan dengan matriks SWOT berdasarkan hasil strategi yang didapatkan pada Matriks IE, yaitu penetrasi pasar, pengembangan pasar, dan pengembangan produk yang tersaji pada Tabel 4.7 diatas.

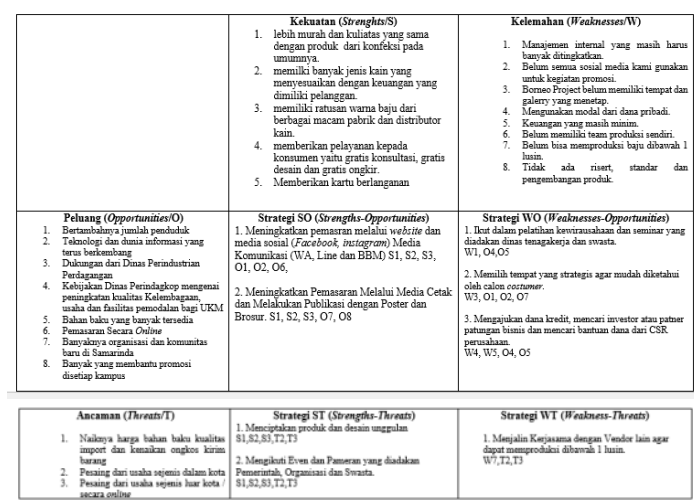

Gambar 3. Hasil SWOT Borneo Project

Strategi-strategi tersebut dapat dijabarkan sebagai berikut:

1. Strategi SO

Strategi ini dibuat untuk memanfaatkan kekuatan internal dan peluang sebesarbesarnya. Strategi SO yang dibuat adalah sebagai berikut:

a. Meningkatkan pemasran melalui website dan media sosial (Facebook, instagram) Media Komunikasi (WA, Line dan BBM) dan,

b. Meningkatkan Pemasaran Melalui Media Cetak dan Melakukan Publikasi dengan Poster dan Brosur.

2. Strategi ST

Strategi ini untuk menggunakan kekuatan internal yang dimiliki perusahaan dengan cara menghindari ancaman eksternal. Strategi ST yang dibuat adalah :

a. Ikut dalam pelatihan kewirausahaan dan seminar yang diadakan dinas tenagakerja dan swasta, b. Memilih tempat yang strategis agar mudah diketahui oleh calon costumer dan,

c. Mengajukan dana kredit, mencari investor atau partner patungan bisnis dan mencari bantuan dana dari CSR perusahaan.

\section{Strategi WO}

Strategi ini diterapkan dengan memanfaatkan peluang eksternal dan mengatasi kelemahan-kelemahan internal. Strategi WO yang dibuat adalah sebagai berikut:
a. Menciptakan produk dan desain unggulan dan,
b. Mengikuti Even dan Pameran yang diadakan Pemerintah, Organisasi dan Swasta.

4. Strategi WT

Strategi ini didasarkan pada kegiatan yang bersifat defensif dan ditujukan

meminimalkan kelemahan internal serta menghindari ancaman eksternal. Strategi WT yang dibuat adalah Menjalin Kerjasama dengan Vendor lain agar dapat memproduksi dibawah 1 lusin.

\subsection{Matrik QSPM}

Berdasarkan hasil perhitungan Total Attractive Score (TAS), alternatif strategi yang paling menarik dan diprioritaskan untuk diterapkan oleh Borneo Project dalam memasarkan produk Bajunya adalah mengajukan dana kredit, mencari investor atau partner patungan bisnis dan mencari bantuan dana dari CSR perusahaan dengan Total Attractive Score sebesar 5.824.

Tabel 5. Analisis Strategi Borneo Project

\begin{tabular}{|c|c|c|c|}
\hline No & Alternatif Strategi & TAS & Peringkat \\
\hline 1 & $\begin{array}{l}\text { Meningkatkan pemasran melalui website dan media sosial } \\
\text { (Facebook, instagram) Media Komunikasi (WA, Line dan } \\
B B M)\end{array}$ & 5,196 & 5 \\
\hline 2 & $\begin{array}{l}\text { Meningkatkan Pemasaran Melalui Media Cetak dan } \\
\text { Melakukan Publikasi dengan Poster dan Brosur }\end{array}$ & 5,156 & 6 \\
\hline 3 & $\begin{array}{l}\text { Ikut dalam pelatihan kewirausahaan dan seminar yang } \\
\text { diadakan dinas tenagakerja dan swasta. }\end{array}$ & 5,256 & 4 \\
\hline 4 & $\begin{array}{l}\text { Memilih tempat yang strategis agar mudah diketahui oleh } \\
\text { calon costumer. }\end{array}$ & 5,657 & 2 \\
\hline 5 & $\begin{array}{l}\text { Mengajukan dana kredit, mencari investor atau partner } \\
\text { patungan bisnis dan mencari bantuan dana dari CSR } \\
\text { perusahaan. }\end{array}$ & 5,824 & 1 \\
\hline 6 & Menciptakan produk dan desain unggulan. & 5,088 & 7 \\
\hline 7 & $\begin{array}{l}\text { Mengikuti Even dan Pameran yang diadakan Pemerintah, } \\
\text { Organisasi dan Swasta }\end{array}$ & 4,899 & 8 \\
\hline 8 & $\begin{array}{l}\text { Menjalin Kerjasama dengan Vendor lain agar dapat } \\
\text { memproduksi dibawah } 1 \text { lusin. }\end{array}$ & 5,345 & 3 \\
\hline
\end{tabular}


Dengan Mengajukan dana kredit, mencari investor atau partner patungan bisnis dan mencari bantuan dana dari CSR perusahaan.diharapakan mampu menambah modal bagi Borneo Project sehingga bisa dilakukan promosi di semua media dan lebih mengembangkan usaha.

\section{Kesimpulan dan Saran}

\subsection{Kesimpulan}

1. Berdasarkan hasil penelitian yang dilakukan mengenai "Analisis Sstrategi Pemasaran Menggunakan Metode Quantitative Strategic Planning Matrix (QSPM) (Studi Kasus: Borneo Project)", maka didapatkan kesimpulan sebagai berikut:

Berdasarkan hasil wawancara yang dilakukan didapatkan faktor internal (kekuatan dan kelemahan) dan faktor eksternal (peluang dan ancaman) yang mempengaruhi pemasaran Pruduk dari Borneo Project. Adapun Kekuatan dari Borneo Project adalah harga lebih murah dan kuliatas yang sama dengan produk dari konfeksi pada umumnya, memilki banyak jenis kain yang menyesuaikan dengan keuangan yang dimiliki pelanggan, memiliki ratusan warna baju dari berbagai macam pabrik dan distributor kain,memberikan pelayanan kepada konsumen yaitu gratis konsultasi, gratis desain dan gratis ongkir,memberikan kartu berlanganan. Kelemahan yang dimiliki adalah Manajemen internal yang masih harus banyak ditingkatkan, belum semua sosial media di gunakan untuk kegiatan promosi, Borneo Project belum memiliki tempat dan galerry yang menetap,mengunakan modal dari dana pribadi, keuangan yang masih minim belum memiliki team produksi sendiri, belum bisa memproduksi baju dibawah 1 lusin,tidak ada risert, standar dan pengembangan produk. Peluang yang ada diantaranya dalah Bertambahnya jumlah penduduk, teknologi dan dunia informasi yang terus berkembang, dukungan dari Dinas Perindustrian, kebijakan Dinas Perindustrian mengenai peningkatan kualitas Kelembagaan, usaha dan fasilitas pemodalan bagi UKM, Bahan baku yang banyak tersedia, Pemasaran Secara Online, Banyaknya organisasi dan komunitas baru di Samarinda, Banyak yang membantu promosi disetiap kampus. Sedangkan ancaman yang dimiliki Borneo Project adalah: kondisi ekonomi yang belum stabil mengakibatkan kenaikan harga, Pesaing dari usaha sejenis dalam kota, Pesaing dari usaha sejenis luar kota atau secara online.

2. Berdasarkan perumusan strategi yang dilakukan pada tahap pencocokan, didapatkan delapan strategi. Dari kedelapan alternatif strategi tersebut, didapatkan strategi yang paling diprioritaskan berdasarkan peringkat strategi, yaitu Mengajukan dana kredit, mencari investor atau partner patungan bisnis dan mencari bantuan dana dari CSR perusahaan. dengan Total Attractive Score sebesar 5,699.

\subsection{Saran}

Berdasarkan penelitian yang dilakukan, maka terdapat beberapa saran yang dapat diberikan, yaitu sebagai berikut:

1. Bagi Borneo Project harus terus berusaha mempertahankan dan meningkatkan kualitas produk-produk yang dimiliki, sehingga dapat menarik dan meningkatkan konsumen,

2. Membuat perizinan usaha dan membuat $\mathrm{Cv}$ atau PT agar usaha ini bisa legal dan dapat mengikuti tender pengadaan seragam untuk pegawai di pemerintahan atau swasta dan,

\section{Daftar Pustaka}

David, F.R., 2009, Strategic Management: Konsep. Jilid 1, ed. 12, Salemba Empat, Jakarta.

Kolter, P., Keller, K.L., 2009, Manajemen Pemasaran, Jilid 1, Edisi 12, Erlangga, Jakarta.

Mahfud, T. 2017. Aplikasi Metode QSPM (Quantitative Strategic Planning Matrix) Studi Kasus: Strategi Peningkatan Mutu Lulusan Program Studi Tata Boga). ISSN 2580 - 5398. Vol.1 No 1.

Mas'ud E,Imam S.2016. Analisis Strategi Pemasaran menggunakan Metode Quantitative Strategic Planning Matrix 
(QSPM)(Studi Kasus Di Restoran Waroeng Steak and Shake Cabang Soekarno Hatta, Malang). Vol. 5 No 1: 46-53.

Puspitasari N,. B., Rumita., Rani, Pratama G. Y., 2013. Pemilihan strategi bisnis dengan menggunakan QSPM (quantitative strategic planning matrix) dan model maut (multi attribute utility theory) (studi kasus pada sentra industri gerabah kasongan, Bantul, yogyakarta). Vol VIII, No 3

Purwandari, S., 2015, Analisis Quantitative Strategic Planning Matrix (QSPM) sebagai Landasan Menentukan Strategi Pemasaran Pada SMK Citra Medika Sukoharjo, Jurnal Sainstech Politeknik Indonusa Surakarta, ISSN 2355-5009, Politeknik Indonusa, Surakarta.
Rangkuti, F., 2006, Analisis SWOT Teknik Membedah Kasus Bisnis, Cetakan ke 13, Gramedia Pustaka Utama, Jakarta Sunyoto., S., 2015, Manajemen Pemasaran Jasa, Caps, yogyakarta.

Suharno., dan Sutarso, Y., 2010, Marketing in Practice, Graha Ilmu, Yogyakarta.

Biro Pusat Statistik, 2018, www.bps.go.id diakses 20 Juli 2018 pukul 14.00 .

Kamus Besar Bahasa Indonesia, 2017, www.kbbi.web.id/konfeksi/ diakses 18 Oktober 2017 pukul 14.00. 
Halaman ini sengaja dikosongkan

This page is intentionally left blank 